\title{
The Striopallidal Neuron: A Main Locus for Adenosine-Dopamine Interactions in the Brain
}

\author{
Sergi Ferré,' William T. O'Connor, ${ }^{2}$ Kjell Fuxe, ${ }^{3}$ and Urban Ungerstedt ${ }^{2}$ \\ 'Department of Neurochemistry, C.S.I.C., 08034 Barcelona, Spain and ${ }^{2}$ Department of Pharmacology and ${ }^{3}$ Department of \\ Histology and Neurobiology, Karolinska Institute, 10401 Stockholm, Sweden
}

\begin{abstract}
Recent pharmacological data suggest that a receptor-receptor interaction between adenosine $A_{2}$ and dopamine $D_{2}$ receptors in the brain underlies the behavioral effects of adenosine agonists and adenosine antagonists, such as caffeine and theophylline. According to this interaction, stimulation of $A_{2}$ receptors inhibits and their blockade potentiates the effects of $D_{2}$ receptor stimulation. Furthermore, both $A_{2}$ and $D_{2}$ receptors are selectively colocalized on GABAergic striopallidal neurons. In this microdialysis investigation the effect of intrastriatal infusion of adenosine and dopamine agonists and antagonists alone or in combination was studied on the release of GABA from the terminals of the striopallidal neuron in awake, freely moving rats. We report that the GABAergic striopallidal neuron, which is a key component of the indirect striatal efferent pathway, is a main locus for $A_{2}-D_{2}$ interactions in the brain and possibly a main target for the central actions of adenosine agonists and antagonists.
\end{abstract}

[Key words: adenosine $A_{2}$ receptor, dopamine $D_{2}$ receptor, GABA, striopallidal neuron, receptor-receptor interaction, methylxanthines]

Behavioral and biochemical evidence suggests that a strong and specific interaction between adenosine $A_{2}$ and dopamine $D_{2}$ receptors exists in the brain. Behavioral data show that stimulation and blockade of the $A_{2}$ receptor inhibits and potentiates, respectively, $\mathrm{D}_{2}$-mediated locomotor activation in mice (Ferré et al., 1991a,b) while stimulation of $D_{2}$ receptors counteracts the $\mathrm{A}_{2}$-mediated cataleptic effect in rats (Ferré et al., 1991c). Biochemical data show that $A_{2}$ receptor stimulation decreases both the affinity of $\mathrm{D}_{2}$ receptors for dopamine agonists (Ferré et al., 1991d) and $\mathrm{D}_{2}$ transduction (Ferré and Fuxe, 1992; Ferré ct al., 1993) in rat striatal membrane preparations. Based on these pharmacological findings we postulated that this $A_{2}-D_{2}$ interaction represents a main mechanism underlying the central effects of adenosine agonists and antagonists (for review, see Ferré et al., 1992).

The biochemical data showing an $A_{2}-D_{2}$ interaction with membrane preparations of rat striatum strongly suggested the existence of a colocalization of $A_{2}$ and $D_{2}$ receptors on the same

\footnotetext{
Received Mar. 25, 1993; revised June 11, 1993; accepted June 17, 1993.

We thank A. Cobos for statistical advice. This work was supported by the Ministry of Foreign Affairs of Spain, U.S. Public Health Service Grant MH44211 (Neuroscience Center for Research in Schizophrenia), The Wellcome Trust, and the Swedish Medical Research Council (04X-715).

Correspondence should be addressed to Sergi Ferré, Department of Neurochemistry, C.S.I.C., Jordi Girona 18-26, 08034 Barcelona, Spain.

Copyright (C) 1993 Society for Neuroscience $0270-6474 / 93 / 135402-05 \$ 05.00 / 0$
}

striatal neuron (Ferré et al., 1991d). Both $A_{2}$ receptors and $A_{2}$ receptor mRNA expression are highly enriched in the striatum, nucleus accumbens, and olfactory tubercle (Jarvis and Williams, 1989; Parkinson and Fredholm, 1990; Martínez-Mir et al., 1991; Schiffmann et al., 1991; Fink et al., 1992), areas also associated with high numbers of $\mathrm{D}_{2}$ receptors (Boyson et al., 1986). Furthermore, $A_{2}$ receptor mRNA is selectively expressed in GABAergic striatal neurons also containing $\mathrm{D}_{2}$ receptors (Schiffmann et al., 1991; Fink et al., 1992). These GABA- and enkephalin-containing neurons (Gerfen et al., 1990; Le Moine et al., 1990) project to the globus pallidus constituting the "indirect pathway," one of the two major striatal efferent pathways (Alexander and Crutcher, 1990; Gerfen, 1992). Thus, we have recently postulated that the striopallidal GABAergic neuron is a main locus for $A_{2}-D_{2}$ interactions in the brain and is thus a primary site for the action of adenosine agonists and antagonists (Fcrré ct al., 1992).

In the present in vivo microdialysis study, direct functional evidence is provided that an $A_{2}-D_{2}$ interaction plays a central role in the function of the striopallidal pathway in the awake, freely moving rat. One microdialysis probe was implanted in the striatum, the locus of the striopallidal neuronal bodies and of the hypothetical $A_{2}-D_{2}$ interaction, and a second probe was implanted in the ipsilateral globus pallidus, the locus of the striopallidal nerve terminals, which release the neurotransmitter GABA. By using this experimental preparation in awake, freely moving rats, the effect of the intrastriatal infusion of adenosine and dopamine agonists and antagonists alone or in combination was studied on the release of GABA from the terminals of the striopallidal neuron.

\section{Materials and Methods}

Animals. Male Sprague-Dawley rats (Alab, Stockholm) weighing 350$400 \mathrm{gm}$ were used. Animals were maintained on a standard light-dark cycle and allowed free access to food and water.

Surgery. During surgery the animals were mounted into a Kopf stereotaxic frame and body temperature was continuously maintained at $37^{\circ} \mathrm{C}$ with a temperature controller (CMA 150, Carnegie Medicin, Stockholm, Sweden). The animals were maintained under $1.5 \%$ halothane, $98.5 \%$ air anesthesia (delivered at $1.4 \mathrm{liters} / \mathrm{min}$ ). After exposure of the skull and drilling two burr holes, two microdialysis probes (Carnegie Medicin) were stereotaxically implanted: a large probe, with a $4.0 \times$ $0.5 \mathrm{~mm}$ membrane, was implanted into the neostriatum (coordinates from bregma: AP +0.7, L +3.0, DV - 8.0) and a smaller probe, with a $2.0 \times 0.5 \mathrm{~mm}$ membrane, was implanted into the ipsilateral globus pallidus (AP - 1.1, L +3.1, DV -7.75). The probes were perfused at a rate of $2 \mu \mathrm{l} / \mathrm{min}$ with a modified Ringer solution $(1.2 \mathrm{~mm} \mathrm{CaCl}, 2.7$ $\mathrm{mm} \mathrm{KCl}, 148 \mathrm{~mm} \mathrm{NaCl}$, and $0.85 \mathrm{mM} \mathrm{MgCl}_{2}$ ) (Drew and Ungerstedt, 1991) throughout the implantation procedure and dialysis experiment. The probes were permanently secured with methacrylic cement and two stainless steel screws that were implanted in the skull. 

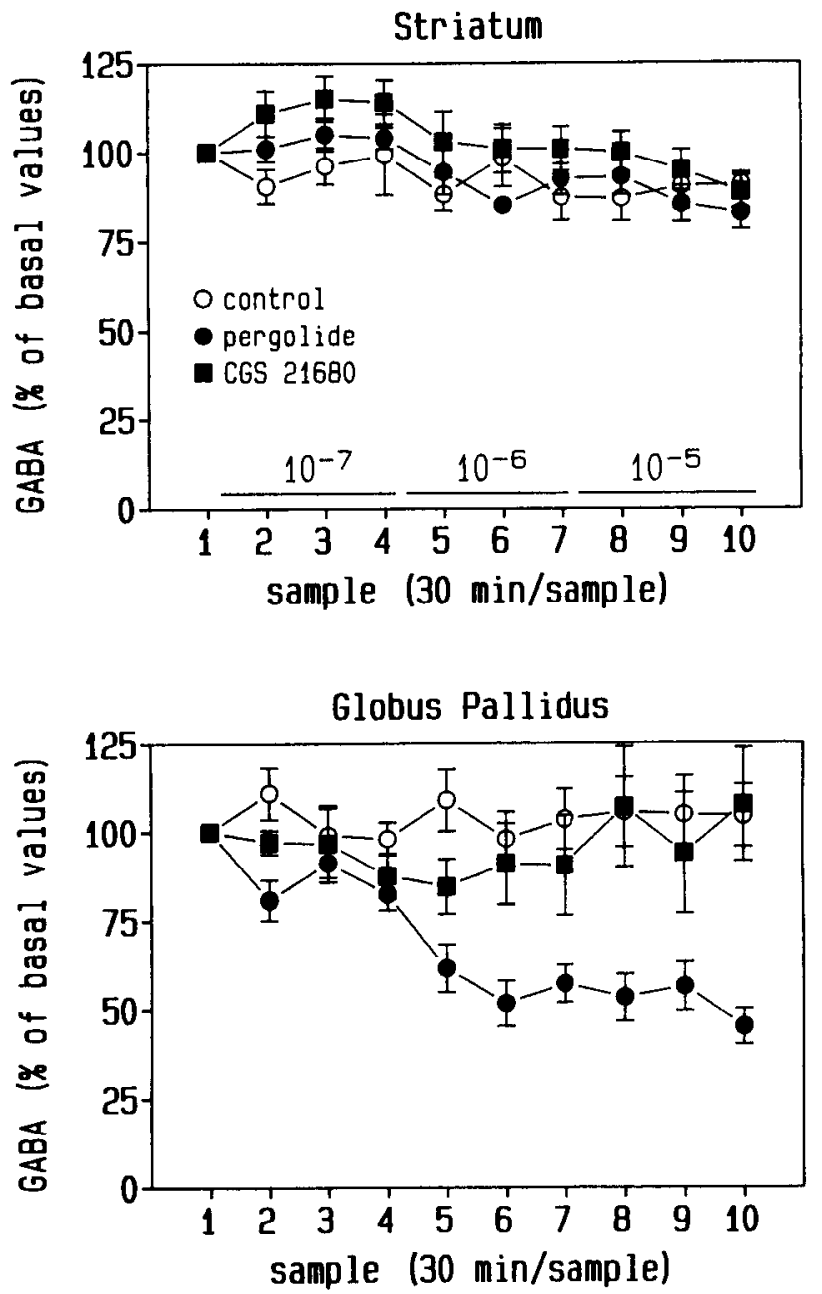

Figure 1. Effect of increasing doses of the intrastriatally infused dopamine $D_{2}$ agonist pergolide and the adenosine $A_{2}$ agonist CGS 21680 on GABA extracellular levels in the striatum and in the ipsilateral globus pallidus of awake, moving rats. The results are expressed as percentage of the three basal values measured prior to drug infusion (means \pm $\mathrm{SEM}, n=5$ or 6/group). Horizontal lines represent the length of time the different drug concentrations were infused. Basal striatal and pallidal GABA levels measured in $30 \mathrm{~min}$ perfusate fractions were, respectively, $17.9 \pm 1.2 \mathrm{nM}(n=18)$ and $11.8 \pm 1.1 \mathrm{nM}(n=16)$.

Microdialysis procedure. The animals were allowed to recover for 48 $\mathrm{hr}$ after probe implantation. To prevent induction of adaptive mechanisms, the experiments were performed in a random order on either the second or third day after surgery. On the day of the experiment the rat was placed in a modified activity bowl. The inlet tubing of the probe was connected to a liquid swivel and perfused with the modified Ringer solution at a flow rate of $2 \mu \mathrm{l} / \mathrm{min}$. The striatal probe was used both to infuse dopamine and adenosine agonists and antagonists and to measure the extracellular concentrations of dopamine and GABA. The pallidal probe was used to measure GABA extracellular levels. Dialysates were collected every 30 min during the experiment. At the end of each experiment the animal was disconnected from the swivel, the inlet and outlet tubings were cut and sealed, and the animal was returned to its home cage. At the end of the study the rats were killed with an overdose of Mebumal (120 mg/kg i.p.; Nord Vacc, Stockholm, Sweden). The brain was removed from the skull and the position of the microdialysis probes was verified by sectioning in a cryostat and microscopic examination.

Dopamine and GABA analysis. Three and 10 microliters of each dialysate sample $(60 \mu \mathrm{l})$ were assayed for dopamine and GABA, respectively. Reverse-phase high-performance liquid chromatograhy (HPLC) with electrochemical detection was used to assay dopamine. The dopamine system consisted of a Sepstick microbore column (in-

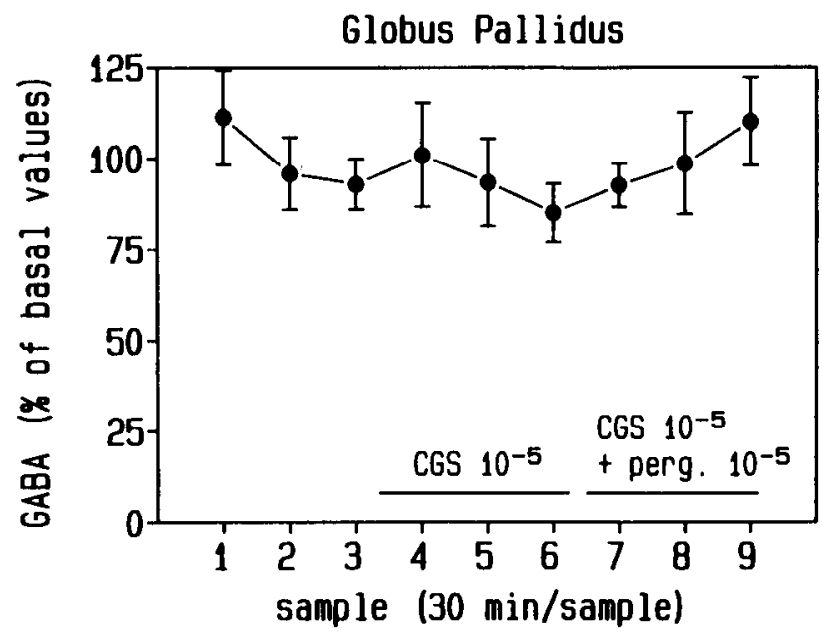

Figure 2. Counteraction of the effect of the intrastriatally infused dopamine $\mathrm{D}_{2}$ agonist pergolide $\left(10^{-5} \mathrm{M}\right)$ (see also Fig. 4) on GABA extracellular levels in the ipsilateral globus pallidus when it was coinfused in the presence of the adenosine $A_{2}$ agonist CGS $21680\left(10^{-5} \mathrm{M}\right)$. CGS 21680 alone was infused $90 \mathrm{~min}$ prior to coinfusion with pergolide. The results are expressed as percentage of the three basal values measured prior to drug infusion (means $\pm \mathrm{SEM}, n=4$ or 5/group). Horizontal lines represent the length of time the different drug combinations were infused. Basal pallidal GABA levels measured in $30 \mathrm{~min}$ perfusate fractions were $10.4 \pm 1.8 \mathrm{nM}(n=4)$.

ternal diameter $=1 \mathrm{~mm}$; length $=10 \mathrm{~cm} ;$ BAS, West Lafayette, IN) containing $3 \mu \mathrm{m}$ ODS packing material, a Spectra Physics (SP) 8810 precision isocratic pump, an on-line CMA 260 degasser (Carnegie Medicin), an SP 4270 integrator, and a BAS LC 4B detector. The composition of the mobile phase for the dopamine system was $0.1 \mathrm{M} \mathrm{NaH}_{2} \mathrm{PO}_{4}, 0.3$ mM EGTA, $1.35 \mathrm{~mm}$ sodium octane sulfonate acid, $4 \%$ acetonitrile, $0.5 \%$ tetrahydrophurane, and $0.1 \mathrm{M}$ acetic acid, $\mathrm{pH} 4.0$. The flow rate of this mobile phase was $70 \mu \mathrm{l} / \mathrm{min}$ and was maintained under isocratic conditions. The limit of sensitivity for dopamine was $2 \mathrm{fmol} / \mathrm{sample}$. The GABA assay employed in this study has been previously described in detail (Kehr and Ungerstedt, 1988). Briefly, the assay was based on precolumn derivatization with $o$-phthaldialdehyde/ $t$-butyl thiol reagent and separation by reverse-phase HPLC on a Nucleosil 3, C18 column with electrochemical detection under isocratic conditions. The mobile phase for the GABA system was $0.15 \mathrm{M}$ Na acetate, $1 \mathrm{mM}$ EDTA, and $50 \%$ acetonitrile, $\mathrm{pH} 5.4$. The flow rate of this mobile phase was 0.8 $\mathrm{ml} / \mathrm{min}$. The limit of sensitivity for GABA was $20 \mathrm{fmol} / \mathrm{sample}$.

\section{Results}

The intrastriatal infusion of the dopamine $\mathrm{D}_{2}$ agonist pergolide (Arnt and Hyttel, 1984; Arnt, 1985) did not change local striatal GABA extracellular levels but caused a significant decrease in GABA extracellular levels in the ipsilateral globus pallidus compared to controls (repeated-measures ANOVA: drug effect, $p<$ 0.001 ; drug effect $\times$ dose effect, $p<0.01$ ). Post hoc comparisons (repeated-measures ANOVA with Newman-Keuls test) showed significant differences between the pergolide-treated group and the control group during the infusion of pergolide at $10^{-6} \mathrm{M}(p$ $<0.01)$ and pergolide at $10^{-5} \mathrm{M}(p<0.01)$ (Fig. 1).

The intrastriatal infusion of the adenosine $\mathrm{A}_{2}$ agonist CGS 21680 (Jarvis et al., 1989; Lupica et al., 1990) did not produce any significant change in striatal or pallidal GABA extracellular levels compared to controls (repeated-measures ANOVA with Newman-Keuls test) (Fig. 1). However, CGS $21680\left(10^{-5} \mathrm{M}\right)$ completely counteracted the effect of pergolide $\left(10^{-5} \mathbf{M}\right)$ on pallidal GABA extracellular levels when they were coinfused in the striatum. Basal pallidal GABA extracellular levels were not statistically different from the GABA levels obtained following the 


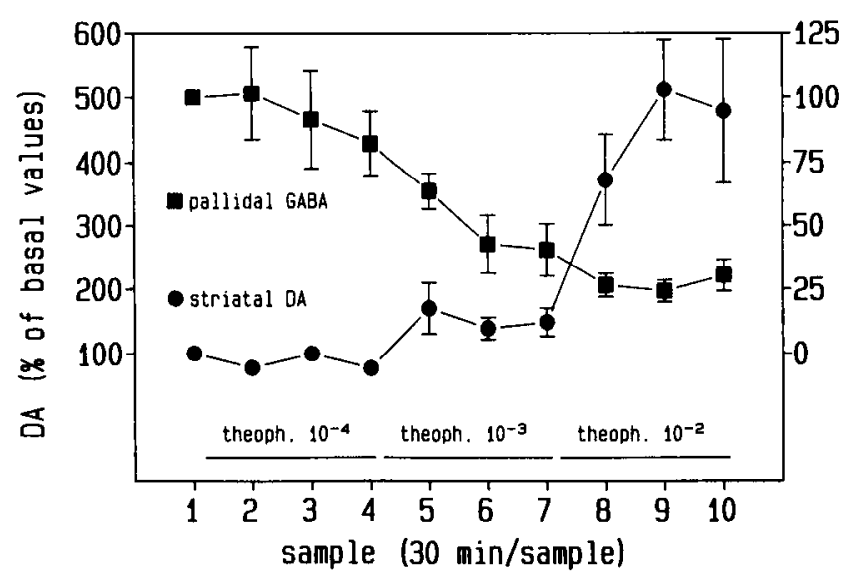

Figure 3. Effect of increasing doses of the intrastriatally infused adenosine antagonist theophylline on dopamine extracellular levels in the striatum and on GABA extracellular levels in the ipsilateral globus pallidus of awake, moving rats. The results are expressed as percentage of the three basal values measured prior to drug infusion (means \pm SEM, $n=4$ or 5/group). Horizontal lines represent the length of time the different drug concentrations were infused. Basal striatal dopamine and pallidal GABA levels measured in 30 min perfusate fractions were $3.0 \pm 0.5 \mathrm{nM}(n=5)$ and $14.4+4.6 \mathrm{nM}(n=4)$, respectively.

infusion of CGS 21680 or the infusion of CGS 21680 plus pergolide (repeated-measures ANOVA, no significant treatment effect) (Fig. 2).

The intrastriatal infusion of the adenosine $A_{1} / A_{2}$ antagonist theophylline (Jarvis et al., 1989) was associated with a dosedependent increase in striatal dopamine extracellular levels (repeated-measures ANOVA: dose effect, $p<0.01$ ). Post hoc comparisons (Newman-Keuls) showed that the effect of theophylline at $10^{-3} \mathrm{M}$ was significantly greater than the effect of theophylline at $10^{-4} \mathrm{M}(p<0.05)$ and that the effect of theophylline at $10^{-2}$ $M$ was significantly greater than the effect of theophylline at $10^{-3}$ M $(p<0.01)$ (Fig. 3). Furthermore, intrastriatal theophylline infusion dose dependently decreased pallidal GABA extracellular levels (repeated-measures ANOVA: dose effect, $p<0.01$ ). Post hoc comparisons (Newman-Keuls) also showed that the effect of theophylline at $10^{-3} \mathrm{M}$ and $10^{-2} \mathrm{M}$ was significantly greater than the effect of theophylline at $10^{-4} \mathrm{M}(p<0.05$ in both cases) (Fig. 3).

The intrastriatal infusion of pergolide at $10^{-5} \mathrm{M}$ and that of pergolide at $10^{-7} \mathrm{M}$ plus theophylline at $10^{-4} \mathrm{M}$ caused a significant decrease in striatal dopamine extracellular levels (repeatedmeasures ANOVA: treatment effect, $p<0.0001$; treatment $\times$ dose effect, $p<0.0001$ ). Post hoc comparisons (Newman-Keuls) showed that the effect of pergolide $10^{-5} \mathrm{M}$ was significantly greater than the effect of pergolide at $10^{-7} \mathrm{M}$ plus theophylline at $10^{-4} \mathrm{M}(p<0.05)$, and that the effect of pergolide at $10^{-7} \mathrm{M}$ plus theophylline at $10^{-4} \mathrm{M}$ was significantly different from the control group $(p<0.01)$ (Fig. 4). Furthermore, the intrastriatal infusion of pergolide and pergolide plus theophylline caused a significant decrease in pallidal GABA extracellular levels (repeated-measures ANOVA: drug effect, $p<0.01$; drug effect $\times$ dose effect, $p<0.01$ ). Post hoc comparisons (Newman-Keuls) showed that the effect of pergolide at $10^{-5} \mathrm{M}$ was not significantly different than the effect of pergolide at $10^{-7} \mathrm{M}$ plus theophylline at $10^{-4} \mathrm{M}$, and that both effects were significantly different from the control group ( $p<0.05$ in both cases) (Fig. 4).
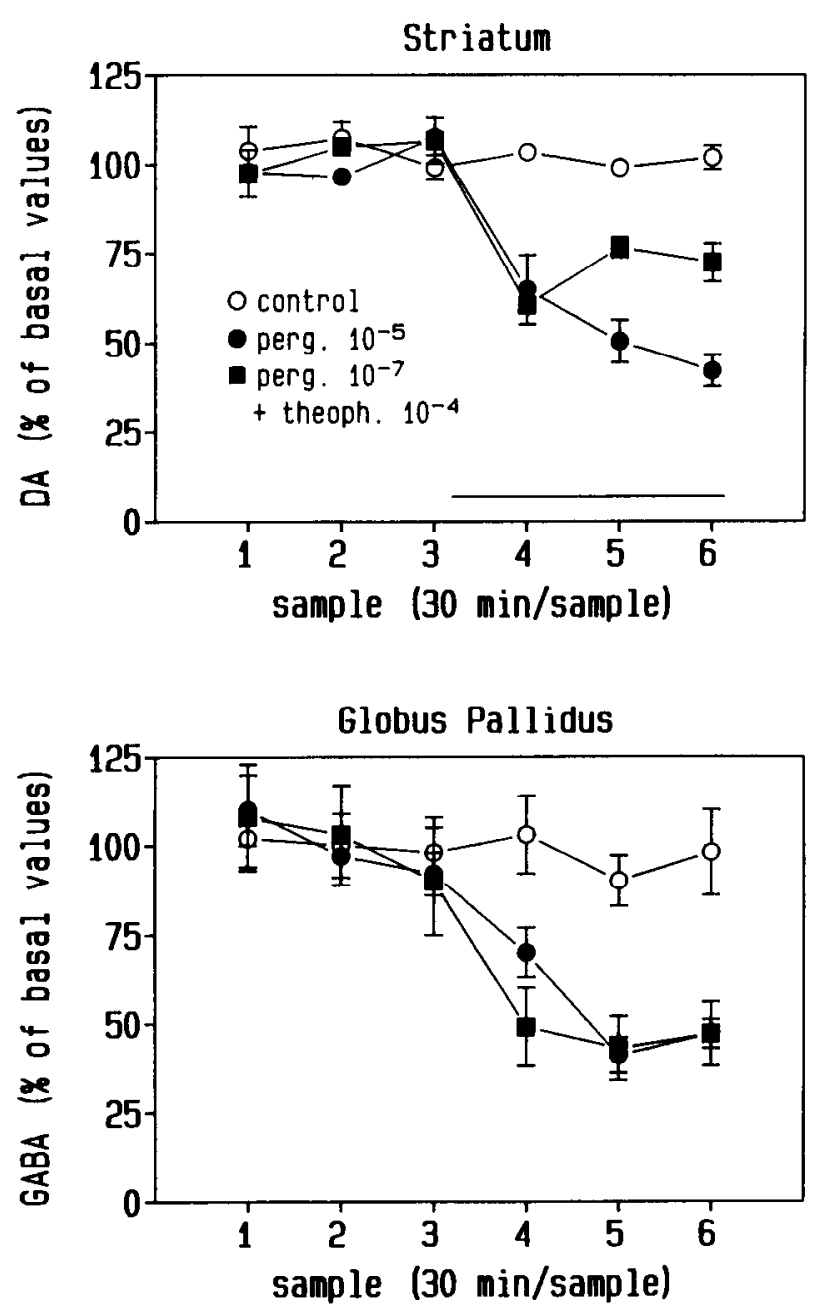

Figure 4. Effect of the intrastriatal coinfusion of the dopamine $\mathrm{D}_{2}$ agonist pergolide $\left(10^{-7} \mathrm{M}\right)$ with the adenosine antagonist theophylline $\left(10^{-4} \mathrm{M}\right)$ on dopamine extracellular levels in the striatum and on GABA extracellular levels in the ipsilateral globus pallidus of awake, moving rats. The effect of the intrastriatal administration of a maximal dose of pergolide $\left(10^{-5} \mathrm{M}\right)$ and a control group were used for comparisons. The results are expressed as percentage of the three basal values prior to drug infusion (means $\pm \mathrm{SEM}, n=4-6$ /group). Horizontal lines represent the length of time the different drug combinations were infused. Basal striatal dopamine and pallidal GABA levels measured in $30 \mathrm{~min}$ perfusate fractions were $3.0 \pm 0.5 \mathrm{nM}(n=14)$ and $12.3 \pm 2.4 \mathrm{nM}(n=$ 13), respectively.

\section{Discussion}

The infusion of the dopamine $\mathrm{D}_{2}$ agonist pergolide (Arnt and Hyttel, 1984; Arnt, 1985) in the striatum caused a strong decrease (up to $50 \%$ ) in the GABA extracellular levels of the ipsilateral globus pallidus without changing striatal GABA levels. With higher levels of calcium into the perfusion medium, a pergolide-induced decrease in striatal GABA levels can also be found (Drew and Ungerstedt, 1991; Fuxe et al., 1992). The striatal infusion of the $A_{2}$ agonist CGS 21680 (Jarvis et al., 1989; Lupica et al., 1990) did not alter either striatal or pallidal GABA levels. However, when the $A_{2}$ agonist was coinfused with the $\mathrm{D}_{2}$ agonist pergolide it completely counteracted the effect of the $\mathrm{D}_{2}$ agonist on pallidal GABA extracellular levels.

Intrastriatal infusion of the $A_{1} / A_{2}$ antagonist theophylline (Jarvis et al., 1989) was associated with a stronger inhibition (75\%) of pallidal GABA levels compared with that for pergolide 
$(50 \%)$. However, the effects of striatal infusion of pergolide and theophylline on striatal dopamine levels were qualitatively different: pergolide caused a decrease (up to $60 \%$ ) and theophylline caused a strong increase (up to $400 \%$ ) of striatal dopamine extracellular levels. These results could be explained by a presynaptic effect of both drugs on dopamine terminals. $D_{2}$ and $A_{1}$ receptors have been shown to modulate, by different mechanisms, striatal dopamine release, the stimulation of either receptor causing inhibition and their blockade causing stimulation of dopamine release (Morgan and Vestal, 1989; Drew et al., 1990; Cass and Zahniser, 1991).

Consequently, the decrease of pallidal GABA levels after the striatal infusion of theophylline could be explained by the striatal theophylline-induced dopamine release, which would stimulate $D_{2}$ receptors on the striopallidal neuron. In fact, theophylline caused a similar but opposite stepwise dose effect in striatal dopamine and pallidal GABA extracellular levels. Nevertheless, a dose of theophylline $(100 \mu \mathrm{M})$, which did not produce any change in striatal dopamine or pallidal GABA levels, caused a strong decrease (of about $50 \%$ ) of pallidal GABA levels when coinfused with a dose of pergolide (100 nM), which was without effect on pallidal GABA levels. Furthermore, this drug combination was associated with a decrease in striatal dopamine levels, strongly indicating that the mechanism involved was an enhancement of postsynaptic $D_{2}$ receptor transduction due to blockade of $\mathrm{A}_{2}$ receptors. Although the presynaptic effect of methylxanthines on the striatal dopamine terminals, that is, an increase in dopamine release, may contribute to the behavioral effects of these drugs, our data suggest that this mechanism of action is only in operation at higher doses. Systemic administration of an optimal dose of theophylline $(20 \mathrm{mg} / \mathrm{kg})$, which causes locomotor activation in the rat, is associated with an extracellular striatal concentration of between $50 \mu \mathrm{M}$ and $90 \mu \mathrm{M}$ (Fredholm et al., 1983; Ståhle et al., 1990). This is in the concentration range most probably reached in the vicinity of the microdialysis probe following intrastriatal infusion of theophylline at $100 \mu \mathrm{M}$ (Ståhle et al., 1990). Thus, the locomotor activation associated with theophylline can be explained on the basis of the presently observed $A_{2}-D_{2}$ interaction on the striopallidal neuron.

These results strongly suggest that, through a postsynaptic $A_{2}$ receptor- $D_{2}$ receptor interaction, the striopallidal neuron is a main locus for the interaction between the neurotransmitter dopamine and the neuromodulator adenosine in the brain and, thus, a main target for adenosine agonists and antagonists. Furthermore, these results suggest that new therapeutic strategies, incorporating specific $\mathrm{A}_{2}$ agonists and antagonists, could be useful in some basal ganglia disorders, like Parkinson's disease and Huntington's chorea, as there is considerable evidence showing that the impairment in the functioning of the striopallidal neuron plays a key role in mediating the symptoms of these disorders (Albin et al., 1989; DeLong, 1990).

\section{References}

Albin RL, Young AB, Penney JB (1989) The functional anatomy of basal ganglia disorders. Trends Neurosci 12:366-375.

Alexander GR, Crutcher MD (1990) Functional architecture and basal ganglia circuits: neural substrates of parallel processing. Trends Neurosci 13:266-271.

Arnt J (1985) Behavioural stimulation is induced by separate dopamine D-1 and D-2 receptor sites in reserpine-pretreated but not in normal rats. Eur J Pharmacol 113:79-88.

Arnt J, Hyttel J (1984) Differential inhibition by dopamine D-1 and
D-2 antagonists of circling behaviour induced by dopamine agonists in rats with unilateral 6-hydroxy-dopamine lesions. Eur J Pharmacol 102:349-354.

Boyson SJ, McGonigle P, Scatton PB (1986) Quantitative autoradiographic localization of the D1 and D2 subtypes of dopamine receptors in rat brain. J Neurosci 6:3177-3182.

Cass WA, Zahniser NR (1991) Potassium channel blockers inhibit $\mathrm{D}_{2}$ dopamine, but not $A_{1}$ adenosine, receptor-mediated inhibition of striatal dopamine release. J Neurochem 57:147-152.

DeLong MR (1990) Primate models of movement disorders of basal ganglia origin. Trends Neurosci 13:281-285.

Drew KL, Ungerstedt U (1991) Pergolide presynaptically inhibits calcium-stimulated release of gamma-aminobutyric acid. J Neurochem 57:1927-1930.

Drew KL, O'Connor WT, Kehr J, Ungerstedt U (1990) Regional specific effects of clozapine and haloperidol on GABA and dopamine release in rat basal ganglia. Eur J Pharmacol 187:385-397.

Ferré S, Fuxe K (1992) Dopamine denervation leads to an increase in the intramembrane interaction between adenosine $A_{2}$ and dopamine $\mathrm{D}_{2}$ receptors in the neostriatum. Brain Res 594:124-130.

Ferré S, Herrera-Marschitz M, Grabowska-Andén M, Ungerstedt U, Casas M, Andén N-E (1991a) Postsynaptic dopamine/adenosine interaction: I. Adenosine analogues inhibit a D-2 mediated behaviour in short-term reserpinized mice. Eur J Pharmacol 192:30-35.

Fcrré S, Herrera-Marschitz $M$, Grabowska- $\Lambda$ ndén $M$, Ungerstedt $U$, Casas M, Andén N-E (1991b) Postsynaptic dopamine/adenosine interaction: II. Postsynaptic dopamine agonism and adenosine antagonism of methylxanthines in short-term reserpinized mice. Eur $\mathrm{J}$ Pharmacol 192:36-42.

Ferré S, Rubio A, Fuxe K (1991c) Stimulation of adenosine $A_{2}$ receptors induces catalepsy. Neurosci Lett 130:162-164.

Ferré S, von Euler G, Johansson B, Fredholm B, Fuxe K (1991d) Stimulation of high affinity adenosine A-2 receptors decreases the affinity of dopamine D-2 receptors in rat striatal membranes. Proc Natl Acad Sci USA 88:7237-7241.

Ferré S, Fuxe K, von Euler G, Johansson B, Fredholm B (1992) Adenosine-dopamine interactions in the brain. Neuroscience 51:501-512.

Ferré S, Snaprud P, Fuxe K (1993) Opposing actions of an adenosine $A_{2}$ receptor agonist and a GTP analogue on the regulation of dopamine D receptors in rat neostriatal membranes. Eur J Pharmacol [Mol Pharmacol] 244:311-315.

Fink JS, Weaver DR, Rivkees SA, Peterfreund RA, Pollack A, Adler EM, Reppert SM (1992) Molecular cloning of the rat $A_{2}$ adenosine receptor: selective co-expression with $D_{2}$ dopamine receptors in rat striatum. Mol Brain Res 14:186-195.

Fredholm BB, Herrera-Marschitz M, Jonzon B, Lindström K, Ungerstedt $U$ (1983) On the mechanism by which methylxanthines enhance apomorphine-induced rotation behaviour in rats. Pharmacol Biochem Behav 19:535-541.

Fuxe K, O'Connor WT, Antonelli T, Osborne PG, Tanganelli S, Agnati LF, Ungerstedt U (1992) Evidence for a substrate of neuronal plasticity based on pre- and postsynaptic neurotensin-dopamine receptor interactions in the neostriatum. Proc Natl $\Lambda$ cad Sci USA 89:55915595.

Gerfen CR (1992) The neostriatal mosaic: multiple levels of compartmental organization. Trends Neurosci 15:133-139.

Gerfen CR, Engber TM, Mahan LC, Sussel Z, Chase TN, Monsma FJ $\mathrm{Jr}$, Sibley DR (1990) $\mathrm{D}_{1}$ and $\mathrm{D}_{2}$ dopamine receptor-regulated gene expression of strionigral and striopallidal neurons. Science 250:1429 1432.

Jarvis MF, Williams M (1989) Direct autoradiographic localization of adenosine $A_{2}$ receptors in the rat brain. Eur J Pharmacol 168:243246.

Jarvis MF, Schulz R, Hutchison AJ, Do UH, Sills A, Williams M (1989) $\left[{ }^{3} \mathrm{H}\right] \mathrm{CGS} 21680 \mathrm{C}$, an $\mathrm{A}_{2}$ selective adenosine receptor agonist with preferential hypotensive activity. J Pharmacol Exp Ther 251:888893.

Kehr J, Ungerstedt U (1988) Fast HPLC estimation of aminobutyric acid in microdialysis perfusates: effect of nipecotic and 3-mercaptopropionic acids. J Neurochem 51:1308-1310.

Le Moine C, Normand E, Guitteny AF, Fouque B, Teoule R, Bloch B (1990) Dopamine receptor gene expression by enkephalin neurons in rat forebrain. Proc Natl Acad Sci USA 87:230-234.

Lupica CR, Cass WA, Zahniser NR, Dunwiddie V (1990) Effects of the selective adenosine $A_{2}$ receptor agonist CGS 21680 on in vitro 
electrophysiology, cAMP formation and dopamine release in rat hippocampus and striatum. J Pharmacol Exp Ther 252:1134-1141.

Martinez-Mir MI, Probst A, Palacios JM (1991) Adenosine A receptors: selective localization in the human basal ganglia and alterations with disease. Neuroscience 42:697-706.

Morgan ME, Vestal RE (1989) Methylxanthine effects on caudate dopamine release as measured by in vivo electrochemistry. Life Sci 45:2025-2039.

Parkinson FE, Fredholm BB (1990) Autoradiographic evidence for G-protein coupled $\mathrm{A}_{2}$-receptors in rat neostriatum using [ $\left.{ }^{3} \mathrm{H}\right]-\mathrm{CGS}$
21680 as a ligand. Naunyn Schmiedebergs Arch Pharmacol 342:8589.

Schiffmann SN, Jacobs O, Vanderhaeghen J-J (1991) Striatal restricted adenosine $A_{2}$ receptor (RDC8) is expressed by enkephalin but not by substance $P$ neurons: an in situ hybridization histochemistry study. J Neurochem 57:1062-1067.

Ståhle L, Segersvärd S, Ungerstedt U (1990) Theophylline concentration in the extracellular space of the rat brain: measurement by microdialysis and relation to behaviour. Eur J Pharmacol 185:187-193. 